\title{
Thermophysics Characterization of Kerosene Combustion
}

\author{
Ten-See Wang ${ }^{\prime}$ \\ NASA Marshall Space Flight Center, Huntsville, Alabama 35812 \\ Email: Ten-see.Wang@msfc.nasa.gov
}

\begin{abstract}
$\underline{\text { Abstract }}$
A one-formula surrogate fuel formulation and its quasi-global combustion kinetics model are developed to support the design of injectors and thrust chambers of kerosene-fueled rocket engines. This surrogate fuel model depicts a fuel blend that properly represents the general physical and chemical properties of kerosene. The accompanying gaseous-phase thermodynamics of the surrogate fuel is anchored with the heat of formation of kerosene and verified by comparing a series of one-dimensional rocket thrust chamber calculations. The quasi-global combustion kinetics model consists of several global steps for parent fuel decomposition, soot formation, and soot oxidation, and a detailed wet-CO mechanism. The final thermophysics formulations are incorporated with a computational fluid dynamics model for prediction of the combustor efficiency of an uni-element, tri-propellant combustor and the radiation of a kerosene-fueled thruster plume. The model predictions agreed reasonably well with those of the tests.
\end{abstract}

\section{Nomenclature}

A $\quad=$ pre-exponential factor

Copyright (C) 2000 by the American Institute of Aeronautics and Astronautics, Inc. No copyright is asserted in the United States under Title 17, U.S. Code. The U.S. Government has a royalty-free license to exercise all rights under the copyright claimed herein for Governmental purposes. All other rights are reserved by the copyright owner.

'Team Lead, Applied Fluid Dynamics Analysis Group, Space Transportation Directorate, Senior Member AIAA. 


$$
\begin{array}{ll}
\mathrm{C}_{\mathrm{p}} & =\text { heat capacity } \\
\mathrm{E} & =\text { activation energy } \\
\mathrm{H} & =\text { enthalpy } \\
\mathrm{K} & =\text { forward rate constant } \\
\mathrm{P} & =\text { pressure, atm } \\
\mathrm{Q} & =\text { radiative heat flux, }, \mathrm{btu} / \mathrm{ft}^{2}-\mathrm{s} \\
\mathrm{R} & =\text { universal gas constant } \\
\mathrm{S} & =\text { entropy } \\
\mathrm{T} & =\text { temperature, } \mathrm{K} . \\
\alpha & =\text { species mass fraction } \\
\theta & =\text { view angle, deg }
\end{array}
$$

\section{Subscripts}

$$
\begin{array}{ll}
\mathrm{c} & =\text { combustion or chamber } \\
\mathrm{f} & =\text { formation or forward reaction }
\end{array}
$$

\section{Introduction}

Russian-built kerosene-fueled rocket engines such as $\mathrm{RD}-170^{1}$ or its U.S. proposed counterparts such as RD-704 and NASA MSFC developed Fastrac engines have been identified as potential candidates to fly the Single-Stage-to-orbit Reusable Launch Vehicles. In order to support the associated engineering issues, specifically the preliminary conceptual design and evaluation of the performance of the injectors and thrust chambers using Computational Fluid Dynamics (CFD), accurate and computationally efficient models that properly represent the thermophysics, namely 
fuel formula, thermodynamics, and finite-rate combustion-kinetics, have to be used. Unfortunately, models pertaining to these aspects were underdeveloped.

In this study, based on reported physical-chemical property data, a one-formula surrogate fuel is proposed as a generic representation for kerosene, or its derived fuel RP-1. The thermodynamics of the surrogate fuel such as heat capacity, enthalpy and entropy are generated and the rationale for generation is given. A kerosene combustion kinetics is proposed based on a quasi-global kinetics format and the rationale for which, including the specific reactions chosen, is also given. The final thermophysics characterization is implemented in a CFD model and benchmarked on two rocket applications: the combustion efficiency of an experimental tri-propellant combustor and the radiation of a test rocket plume.

\section{One-Formula Surrogate Fuel Model}

Common hydrocarbon rocket fuels such as kerosene, or jet fuels are derived from petroleum, while RP-1 is a straight run kerosene fraction ${ }^{2,3}$. These hydrocarbon fuels are complex mixtures of many components and their exact composition and properties vary from batch to batch. Some information on these substances has been reported in the literature. For example, it is reported ${ }^{4}$ that kerosene typically consists of ten hydrocarbons containing 10-16 carbon atoms per molecule, while the constituents include n-dodecane, alkyl derivatives of benzene, naphthalene and its derivatives. Also, at least 87 identifiable hydrocarbons are reported in RP-1 $1^{5}$.

It is obvious that using all 87 identifiable hydrocarbons to represent RP-1, or even ten species for kerosene would be highly inefficient in any kind of performance calculations. A surrogate fuel model composed of a neat compound or several neat components for kerosene-derived fuels has to be developed, while important thermo-physical properties are retained. Such a 
simplification is necessary for computation-intensive design calculation using complex fuels or blends. Conventionally, elemental formulas such as $\mathrm{CH}_{1.9423}$ and its derived standard heat of formation have been used in one-dimensional theoretical rocket performance calculations ${ }^{6}$ for JP-4/RP-1 powered engines. However, elemental formulas have severe limitations when design calculations other than one-dimensional performance is desired, especially those using CFD codes where molecular fuel formulas are preferred. In the past, several non-elemental oneformula surrogate fuel models were proposed. For example, one-formula models $\mathrm{C}_{10} \mathrm{H}_{19}{ }^{7}$ and $\mathrm{C}_{12} \mathrm{H}_{23}{ }^{4}$ were used to represent kerosene, whereas $\mathrm{C}_{12} \mathrm{H}_{26}{ }^{8,9}$ was used to replace RP-1. The simplistic nature of these one-formula fuel models makes them easy to use. However, these simple formulas also present subtle problems when used in performance calculations. For example, when comparing to the physical-chemical properties of kerosene and RP-1, the molecular weight of $\mathrm{C}_{10} \mathrm{H}_{19}$ is too low, the $\mathrm{H} / \mathrm{C}$ ratio of $\mathrm{C}_{12} \mathrm{H}_{23}$ is too low and that of $\mathrm{C}_{12} \mathrm{H}_{26}$ is too high. Furthermore, $\mathrm{C}_{12} \mathrm{H}_{26}$ (n-dodecane) is a paraffin while kerosene normally contains only $41 \%$ non-cyclic hydrocarbons.

Other than the elemental formula and one-formula fuel models, a more detailed modeling approach is the multiple-formula models. For example, Farmer and Anderson ${ }^{5}$ used a threeformula surrogate fuel model to represent RP-1, i.e., $17.4 \% \mathrm{C}_{13} \mathrm{H}_{12}$ (methylbiphenyl), $45.4 \%$ $\mathrm{C}_{12} \mathrm{H}_{24}$ (n-heptylcyclopentane), and $37.2 \% \mathrm{C}_{12} \mathrm{H}_{28}$ (n-tridecane). With multiple molecules, the physical-chemical properties of kerosene or RP-1 may be matched better. However, this approach often creates extra number of chemical species thereby slowing down the computation. Weighing the advantages and disadvantages of the one-formula and multiple-formula approaches, a one-formula surrogate fuel $\mathrm{C}_{12} \mathrm{H}_{24}$ is hereby proposed as a generic representation for kerosene or RP-1, mainly for computational efficiency reason since only one parent fuel is 
involved. In addition, although $\mathrm{C}_{12} \mathrm{H}_{24}$ takes the form of a one-formula surrogate fuel, it is modeled (kinetically) as $41.7 \%$ paraffin and $58.7 \%$ naphthene, thereby matching the approximate paraffin/naphthene split of $41 / 56 .^{2,3}$ In fact, $\mathrm{C}_{12} \mathrm{H}_{24}$ does not represent a certain molecule, rather a mixture of many neat components that has the same averaged thermo-physical-chemical characterization as that of the reported kerosene/RP-1. Therefore $\mathrm{C}_{12} \mathrm{H}_{24}$ has the advantages of a multiple-formula surrogate fuel without being represented as multiple fuels. In summary, the (averaged) molecular weight, elemental formula and formula weight, and the paraffin/naphthene split of the surrogate fuel $\mathrm{C}_{12} \mathrm{H}_{24}$ match reasonably well with those of reported kerosene and RP1, as shown in Table 1. The paraffin-to-naphthene split is an important factor to match in terms of accurate soot prediction since soot forms much easier from naphthene than from paraffin. This point will be elaborated in the quasi-global combustion kinetics section. Notice the small amount of aromatics and olefins in kerosene and RP-1 are ignored and lumped into the paraffins and naphthenes of the surrogate fuel model.

Table 1. Comparison of thermo-physical-chemical characterization of model fuel with reported data.

\begin{tabular}{lccc}
\hline & Kerosene & $\mathrm{RP}-1$ & Surrogate fuel \\
\hline Molecular Formula & $175^{10}$ & $172-175^{2}$ & $\mathrm{C}_{12} \mathrm{H}_{24}$ \\
Molecular Weight & & $\mathrm{CH}_{1.95}-\mathrm{CH}_{2.0}{ }^{2}$, & 168 \\
Elemental Formula & $\mathrm{CH}_{1.9423^{6}, \mathrm{CH}_{1.953}{ }^{10}}$ & $\mathrm{CH}_{2.0}$ \\
& $13.97-14.03^{3}, 13.97^{6}$ & 14.03 \\
\hline
\end{tabular}




\begin{tabular}{lccc}
\hline $\mathrm{H}_{\mathrm{c}}, \mathrm{kcal} / \mathrm{g}$ & $-10.278^{3}$, & $-10.241^{3}$, & -10.278 \\
& $-10.321^{7}$ & $-10.356^{6}$ & \\
$\mathrm{H}_{\mathrm{f}, 298 \mathrm{~K}}, \mathrm{kcal} / \mathrm{mole}$ & & $-5.430^{6} / \mathrm{CH}_{1.9423}$ & $-92.200 / \mathrm{C}_{12} \mathrm{H}_{24}$, \\
& & & $-7.683 / \mathrm{CH}_{2.0}$ \\
$\mathrm{C}_{\mathrm{p} .516 \mathrm{k} . \mathrm{l} \mathrm{atm} \mathrm{cal} / \mathrm{mole}-\mathrm{K}}$ & $101^{2}$ & 103 \\
Paraffins (n \& iso) \% & & $41^{2}$ & 41.7 \\
Naphthenes \% & $56^{2}$ & 58.3 \\
Aromatics \% & $5^{3}$ & $5^{11}, 3^{2}$ & 0 \\
Olefins \% & $1^{3}$ & $0^{2}$ & 0 \\
\hline \hline
\end{tabular}

\section{Gaseous-Phase Surrogate Fuel Thermodynamics Generation}

An important thermodynamic property to be considered for the surrogate fuel is the heat of formation if accurate heat release during combustion is to be predicted. In general, the heat of formation can not be measured directly but must be determined indirectly from its heat of combustion, measurable calorimetrically. The heat of formation for the surrogate fuel is therefore determined by matching its heat of combustion with that of kerosene/RP- 1 . This is accomplished by writing a complete combustion reaction for $\mathrm{C}_{12} \mathrm{H}_{24}$ :

$$
\mathrm{C}_{12} \mathrm{H}_{24}+18 \mathrm{O}_{2} \rightarrow 12 \mathrm{CO}_{2}+12 \mathrm{H}_{2} \mathrm{O}
$$


The heat of reaction of the above equation is the heat of combustion. By definition, the net heat of combustion is obtained when the product $\mathrm{H}_{2} \mathrm{O}$ is at its gaseous state. The heat of formation of the surrogate fuel is written as

$$
\mathrm{H}_{\mathrm{f}, \mathrm{C} 12 \mathrm{H} 24}=12 \mathrm{H}_{\mathrm{f}, \mathrm{CO} 2}+12 \mathrm{H}_{\mathrm{f}, \mathrm{H} 2 \mathrm{O}}-\mathrm{H}_{\mathrm{c}}
$$

The above equation underscores the importance of an appropriate fuel model since the stoichiometry of the combustion reaction determines the value of the molar heat of formation and eventually the amount of combustion products in the engine system. The simplicity of the oneformula surrogate fuel model makes it unnecessary to deal with multiple surrogate fuels, but directly from the reported heating value of kerosene/RP-1. Several reported standard heats of combustion are listed in Table 1. The maximum difference among them is only $0.115 \mathrm{kcal} / \mathrm{g}$ and amounts to about $1 \%$ of the heating value. These values are deemed as consistent and are within the uncertainty bound of the measurement. A midrange value of $-10.278 \mathrm{kcal} / \mathrm{g}$ is chosen. As a result, a thermodynamically consistent heat of formation of $-92.200 \mathrm{kcal} / \mathrm{mole}$ is derived for $\mathrm{C}_{12} \mathrm{H}_{24}$ and a value of $-7.683 \mathrm{kcal} /$ mole is calculated for its elemental form $\mathrm{CH}_{2.0}$, as shown in Table 1.

The next step is to construct the three thermodynamic functions of heat capacity, enthalpy, and entropy as functions of temperature in a usable form. The standard fourth-order polynomial heat capacity form ${ }^{6}$ is used: 


$$
\begin{aligned}
& \frac{C_{p}}{R}=a_{1}+a_{2} T+a_{3} T^{2}+a_{4} T^{3}+a_{5} T^{4} \\
& \frac{H_{T}}{R T}=a_{1}+\frac{a_{2}}{2} T+\frac{a_{3}}{3} T^{2}+\frac{a_{4}}{4} T^{3}+\frac{a_{5}}{5} T^{4}+\frac{a_{6}}{T} \\
& \frac{S_{T}}{R}=a_{1} \ln T+a_{2} T+\frac{a_{3}}{2} T^{2}+\frac{a_{4}}{3} T^{3}+\frac{a_{5}}{4} T^{4}+a_{7}
\end{aligned}
$$

The enthalpy of the surrogate fuel is constructed using the heat capacities of n-deodecane, due to the closeness of $n$-dodecane $\left(\mathrm{C}_{12} \mathrm{H}_{26}\right)$ with $\mathrm{C}_{12} \mathrm{H}_{24}$ family of molecules in terms of carbon and hydrogen atomic numbers and the notion ${ }^{4,5}$ that $n$-dodecane is a major component in kerosene/RP-1. Notice the enthalpy (heat) of formation is anchored with the thermodynamically consistent heat of combustion of kerosene/RP-1. Hence, the heating curve generated herein is more realistic than that of Ref. 4 in which the enthalpy of n-dodecane was used as a placeholder. The generated heat capacity for the surrogate fuel matches well with that of RP-1, as indicated in Table 1. The entropy of formation of $n$-dodecane, is used to construct the entropy curve for $\mathrm{C}_{12} \mathrm{H}_{24}$. The resulting least square coefficients fitted for two temperature ranges are listed in Table 2.

Table 2. Thermodynamic coefficients for $\mathrm{C}_{12} \mathrm{H}_{24}$.

\begin{tabular}{lll}
\hline \hline & 1000 to $5000 \mathrm{~K}$ & 300 to $1000 \mathrm{~K}$ \\
\hline $\mathrm{a}_{1}$ & $0.36440206 \mathrm{E}+02$ & $0.39508691 \mathrm{E}+01$ \\
$\mathrm{a}_{2}$ & $0.54614801 \mathrm{E}-01$ & $0.10207987 \mathrm{E}+00$ \\
$\mathrm{a}_{3}$ & $-0.16091151 \mathrm{E}-04$ & $0.13124466 \mathrm{E}-04$ \\
$\mathrm{a}_{4}$ & $0.21478497 \mathrm{E}-08$ & $-0.76649284 \mathrm{E}-07$ \\
$\mathrm{a}_{5}$ & $-0.10131180 \mathrm{E}-12$ & $0.34503763 \mathrm{E}-10$
\end{tabular}


$a_{6}$

$\mathrm{a}_{7}$

Notice that the reported magnitude of the heat of vaporization of kerosene $(0.059 \mathrm{kcal} / \mathrm{g}$ at normal boiling point $)^{2}$ is not only much smaller than that of the heat of combustion, but is also less than the error bound $(0.115 \mathrm{kcal} / \mathrm{g})^{2,3,6,7}$. In addition, the latent heat decreases to zero at critical pressure, as most of the rocket engines are operated at higher pressures. These rationales allow the gaseous-phase thermodynamics to be curve-fitted to $300 \mathrm{~K}$, about $142 \mathrm{~K}$ lower than the normal boiling point $(542 \mathrm{~K})^{2}$ of kerosene. Nevertheless, in actual calculations involving liquid kerosene fuel, the heat capacity and latent heat of vaporization of liquid kerosene ${ }^{12}$ are used for the liquid-phase thermodynamics, as shown in latter sections of this study.

\section{Surrogate Fuel Thermodynamics Validation}

From a thermochemical consistency standpoint, the proposed one-formula surrogate fuel and its thermodynamics can be validated by performing a series of one-dimensional theoretical rocket engine performance calculations, using the thrust chamber specifications and operating conditions of a Russian engine RD-170,10. Fig. 1 shows a comparison of the calculated theoretical chamber and nozzle exit temperatures as a function of mixture ratios for $\mathrm{C}_{12} \mathrm{H}_{24}$ and its elemental formula $\mathrm{CH}_{2.000}$ for the self-consistency test. The calculated temperatures for $\mathrm{C}_{12} \mathrm{H}_{24}$ and $\mathrm{CH}_{2.000}$ coincide, as expected, since their heat of formations are anchored with the chosen heat of combustion at $-10.278 \mathrm{kcal} / \mathrm{g}$. Also shown in Fig. 1, are the results using elemental formula $\mathrm{CH}_{1.9423}$ with heats of formation of $-5.430,-6.613$, and $-7.133 \mathrm{kcal} / \mathrm{mole}$. These values correspond to heats of combustion of $-10.356^{6},-10.278^{3}$, and $-10.241^{2} \mathrm{kcal} / \mathrm{g}$, 
respectively. The difference among the curves is small since the difference in heats of combustion is small, especially in the fuel lean region. When the temperature profiles are compared at the same heat of combustion $(-10.278 \mathrm{kcal} / \mathrm{g})$, the minor difference between $\mathrm{CH}_{2}$ and $\mathrm{CH}_{1.9423}$ curves is the result of their difference in $\mathrm{H} / \mathrm{C}$ ratios.

Fig. 2 shows the predicted theoretical nozzle exit gas composition. Again, the mole fractions resulted from using $\mathrm{C}_{12} \mathrm{H}_{24}$ coincide with those of $\mathrm{CH}_{2.000}$. Graphite carbon $\left(\mathrm{C}_{s}\right)$ and methane gas formed at nozzle exit at low mixture ratios due to fuel rich combustion at low exit temperatures, as expected. These results show that the proposed one-formula surrogate fuel model is suitable for one-dimensional theoretical rocket performance calculations and is thermodynamically consistent. However, it should be noted that the system-engineering type of calculations often overpredict the performance, especially for heavy hydrocarbon fueled engines. This is because performance impacting thermophysical processes such as ignition delay times and vaporization are usually not considered. In addition, other performance impacting and design particular physical processes such as mixing, shock losses, geometry losses, film cooling and boundary layer losses are also not included. And those are motivations for this study.

\section{Quasi-Global Finite-Rate Combustion Kinetics}

\section{Kerosene Decomposition and Wet-CO Mechanism}

Detailed kinetics mechanism involving elementary steps for parent fuel decomposition is computationally prohibitive for considering kerosene/RP-1 combustion in CFD calculations. On the other hand, one-step ${ }^{4}$ or multiple-step global kinetics models ${ }^{13}$ is computationally efficient, but frequently over-predicts the flame temperature, or not generic enough to take advantage of the modern diagnostic techniques. For example, hydroxyl radical $(\mathrm{OH})$ is usually not involved in those 
models and laser-induced fluorescence imaging of the OH-radical flame structure data ${ }^{14}$ can not be utilized. The quasi-global kinetics that combines several global steps with a detailed wet-CO mechanism is probably best suited for describing complex fuel combustion in a computationally intensive environment. The original quasi-global kinetics ${ }^{15}$ was established based on the observation that straight-chain hydrocarbons and cyclic hydrocarbons have distinctively different ignition delay time characteristics, and that the ignition delay times for straight chain hydrocarbons are similar and so are those for the cyclic hydrocarbons. That important observation led to the development of the original quasi-global kinetics model in which two irreversible global steps are used to describe the decomposition of the straight chain hydrocarbons and the cyclic hydrocarbon into intermediate products, whereas a detailed wet-CO mechanism converts the intermediates into the final combustion products. In the quasi-global kinetics format, $\mathrm{OH}$ radical is not only considered (in the wet mechanism), but plays a vital role in the accurate prediction of the heat release during hydrocarbon combustion. The original quasiglobal kinetics scheme ${ }^{15}$ was evaluated with a variety of simplified flow configurations, including the stirred reactors, plug flow reactors, and turbulent diffusion flames. It was later expanded to an "extended" quasi-global kinetics model ${ }^{16,17}$ in which two more intermediate species and several more global kinetic steps are added to better describe the fuel-rich combustion. In this study, under the premises of computational efficiency and the framework of one-formula surrogate fuel model, the original quasi-global kinetics format is considered. Following that format, two global steps are proposed: one for the paraffin portion and another for the naphthene part of the surrogate fuel. The rates of the two global steps are modified directly from those of the straight chain and cyclic global steps ${ }^{15}$ according to the paraffin and naphthene split in the proposed surrogate fuel $\left(\mathrm{C}_{12} \mathrm{H}_{24}\right)$, thereby satisfying the ignition delay times 
requirement of the original quasi-global kinetics model. The proposed kerosene global steps and the existing CO-wet mechanism are shown in Table 3. The "standard form" in the fourth column of Table 3 means the species concentration terms in the rate expression follows the stoichiometry of the reaction. Also shown in Table 3, the forward reaction rate constant is expressed in the standard Arrhenius form. The backward reaction rate of the reversible reaction is calculated from its forward rate and equilibrium constant.

\section{Soot Formation}

Under fuel rich conditions, kerosene/RP-1 forms soot readily. This is because Naphthene and aromatic hydrocarbons form soot rapidly (condenstaion-polymerization) by directly condensing themselves into polycyclic aromatic hydrocarbons (PAH). On the other hand, paraffins form soot slowly. This is because paraffins have to be break up into smaller fragments first, from which fusing of the fragments occurs to form naphthenes and aromatics, and PAH's form eventually and indirectly (fragmentation-polymerization). ${ }^{18,19}$ These PAH's, also known as soot precursors, are then undergone a series of physical processes to form coagulated soot particles. Frenklach et al. ${ }^{20}$ developed a comprehensive soot formation mechanism in which 180 species and 619 elementary reactions are used in an attempt to describe the aforementioned soot formation processes. However, at the present moment, it is far too expensive to be incorporated into a CFD code while the oxidation of those 180 species was not even considered. Nickerson and Johnson ${ }^{9}$ abridged Frenklach et al.'s model to 19 reactions for prediction of the soot formation in LOX/RP- 1 injectors. However, their model completely ignored the fast condensation-polymerization process, and a soot formation mechanism of 19 reactions is still of considerable size. A global step that makes soot directly from $\mathrm{C}_{12} \mathrm{H}_{24}$ is used instead, as shown in Table 3. For convenience, pseudo-gas graphite 
carbon $\left(\mathrm{C}_{\mathrm{s}}\right)$ is used to represent soot. The forward reaction rate is modified from that established for toluene combustion in jet-stirred combustors and shock tubes. ${ }^{16,17,21}$ The effects of both condensation-polymerization and fragmentation-polymerization are included in this global step.

\section{Heterogeneous Soot Oxidation}

The rates of carbon oxidation were first measured and fitted with a heterogeneous reaction model involving three elementary steps and two active carbon sites to forming $\mathrm{CO}^{22}$ These rates were adopted by several investigators as the rates for heterogeneous soot oxidation. For example, earlier studies ${ }^{16,21}$ used a one-step equation that reacts soot with molecular oxygen to form $\mathrm{CO}_{2}$, whereas the reaction rates are those of Ref. 22 but the rate expression was modified slightly. In 1995, $\mathrm{Hier}^{23}$ reported that Roth et al. ${ }^{24}$ and Olander et al. ${ }^{25}$ independently confirmed that the reaction forming $\mathrm{CO}$ is much more likely than that forming $\mathrm{CO}_{2}$. Roth et al. ${ }^{24}$ used laser absorption to confirm the presence of $\mathrm{CO}$ and the absence of $\mathrm{CO}_{2}$, whereas Olander et al. ${ }^{25}$ used mass spectrometry to determine that the reaction forming $\mathrm{CO}$ was at least two orders of magnitude more probable than that forming $\mathrm{CO}_{2}$. Based on those assertions, this study simplifies the three-step reactions ${ }^{22}$ to a one-step global kinetics forming $\mathrm{CO}$, while maintaining the original rates and the heterogeneous rate expression form ${ }^{22}$, as shown in Table 3.

\section{Homogeneous Soot Oxidation}

Not only is the $\mathrm{OH}$ radical an important controlling species of the heat release in combustion processes, as noted by one of the major premise of the quasi-global kinetics. There is evidence that $\mathrm{OH}$ dependent oxidation of the soot needs to be considered under many flame conditions, especially in hydrocarbon fueled exhaust plumes. ${ }^{26,27}$ The $\mathrm{OH}$ dependent homogeneous soot 
oxidation reaction of Slack et al. ${ }^{26}$ is included in the kerosene quasi-global combustion kinetics so that the effect of soot thermal non-equilibrium on plume characteristics can be assessed, as shown in Table 3. Notice this reaction is endothermic, whereas the heterogeneous soot oxidation reaction is exothermic. Also, in stead of the irreversible reaction in its original form, ${ }^{26}$ a reversible reaction is used in this study since it produces better results with the following validation cases.

Table 3. Kerosene/RP-1 quasi-global combustion kinetics mechanism. $K_{f}=A T^{B} e^{-E / R T}$.

\begin{tabular}{cccccc}
\hline \hline Reaction & A & B & E/R & Form & Ref. \\
\hline Paraffin Global Step & & & & & \\
$\mathrm{C}_{12} \mathrm{H}_{24}+6 \mathrm{O}_{2} \rightarrow 12 \mathrm{CO}+12 \mathrm{H}_{2}$ & $3.888 \mathrm{E} 4$ & 1 & $1.220 \mathrm{E} 4$ & $\mathrm{p}^{0.3}\left[\mathrm{C}_{12} \mathrm{H}_{24}\right]^{0.5}\left[\mathrm{O}_{2}\right]$ & This Work
\end{tabular}

\section{Naphthene Global Step}

$\mathrm{C}_{12} \mathrm{H}_{24}+6 \mathrm{O}_{2} \rightarrow 12 \mathrm{CO}+12 \mathrm{H}_{2} \quad 2.312 \mathrm{E} 7 \quad 1 \quad 1.965 \mathrm{E} 4 \quad \mathrm{p}^{0.3}\left[\mathrm{C}_{12} \mathrm{H}_{24}\right]^{0.5}\left[\mathrm{O}_{2}\right] \quad$ This Work

$\begin{array}{cccccc}\text { Wet-CO Mechanism } & & & & & \\ \mathrm{H}_{2}+\mathrm{O}_{2}=\mathrm{OH}+\mathrm{OH} & 1.700 \mathrm{E} 13 & 0 & 2.407 \mathrm{E} 4 & \text { Standard } & 15,16 \\ \mathrm{OH}+\mathrm{H}_{2}=\mathrm{H}_{2} \mathrm{O}+\mathrm{H} & 2.190 \mathrm{E} 13 & 0 & 2.590 \mathrm{E} 3 & \text { Standard } & 15,16 \\ \mathrm{OH}+\mathrm{OH}=\mathrm{O}+\mathrm{H}_{2} \mathrm{O} & 6.023 \mathrm{E} 12 & 0 & 5.500 \mathrm{E} 2 & \text { Standard } & 15,16 \\ \mathrm{O}+\mathrm{H}_{2}=\mathrm{H}+\mathrm{OH} & 1.800 \mathrm{E} 10 & 1.0 & 4.480 \mathrm{E} 3 & \text { Standard } & 15,16 \\ \mathrm{H}+\mathrm{O}_{2}=\mathrm{O}+\mathrm{OH} & 1.220 \mathrm{E} 17 & -0.91 & 8.369 \mathrm{E} 3 & \text { Standard } & 15,16 \\ \mathrm{M}+\mathrm{O}+\mathrm{H}=\mathrm{OH}+\mathrm{M} & 1.000 \mathrm{E} 16 & 0 & 0 & \text { Standard } & 15,16 \\ \mathrm{M}+\mathrm{O}+\mathrm{O}=\mathrm{O}_{2}+\mathrm{M} & 2.550 \mathrm{E} 18 & -1.0 & 5.939 \mathrm{E} 4 & \text { Standard } & 15,16\end{array}$




$\begin{array}{cccccc}\mathrm{M}+\mathrm{H}+\mathrm{H}=\mathrm{H}_{2}+\mathrm{M} & 5.000 \mathrm{E} 15 & 0 & 0 & \text { Standard } & 15,16 \\ \mathrm{M}+\mathrm{H}+\mathrm{OH}=\mathrm{H}_{2} \mathrm{O}+\mathrm{M} & 8.400 \mathrm{E} 21 & -2.0 & 0 & \text { Standard } & 15,16 \\ \mathrm{CO}+\mathrm{OH}=\mathrm{H}+\mathrm{CO}_{2} & 4.000 \mathrm{E} 12 & 0 & 4.030 \mathrm{E} 3 & \text { Standard } & 15,16 \\ \mathrm{CO}+\mathrm{O}_{2}=\mathrm{CO}_{2}+\mathrm{O} & 3.000 \mathrm{E} 12 & 0 & 2.500 \mathrm{E} 4 & \text { Standard } & 15,16 \\ \mathrm{CO}+\mathrm{O}+\mathrm{M}=\mathrm{CO}_{2}+\mathrm{M} & 6.000 \mathrm{E} 13 & 0 & 0 & \text { Standard } & 15,16\end{array}$

$\underline{\text { Soot Formation Global Step }}$

$\mathrm{C}_{12} \mathrm{H}_{24} \rightarrow 12 \mathrm{C}_{\mathrm{s}}+12 \mathrm{H}_{2} \quad 4.4947 \mathrm{E} 15 \quad-1.94 \quad 1.610 \mathrm{E} 4 \quad\left[\mathrm{C}_{12} \mathrm{H}_{24}\right]^{1.81}\left[\mathrm{O}_{2}\right]^{0.5} \quad$ This Work

Heterogeneous Soot Oxidation
$\mathrm{C}_{\mathrm{s}}+0.5 \mathrm{O}_{2} \rightarrow \mathrm{CO}$
1.0
0.
0.
$72 R_{o x}\left[C_{s}\right] /\left(\rho_{s} D_{s}\right)$
This Work

$\mathrm{R}_{\mathrm{ox}}=\mathrm{K}_{\mathrm{A}} \mathrm{p}_{\mathrm{O} 2} \chi /\left(1+\mathrm{K}_{\mathrm{Z}} \mathrm{p}_{\mathrm{O} 2}\right)$

$+\mathrm{K}_{\mathrm{B}} \mathrm{p}_{\mathrm{O} 2}(1-\chi)$

$\chi=1 /\left(1+\left(\mathrm{K}_{\mathrm{T}} / \mathrm{K}_{\mathrm{B}}\right) \mathrm{p}_{\mathrm{O} 2}\right)$

$\mathrm{K}_{\mathrm{A}}$

$2.0000 \mathrm{E} 1 \quad 0 \quad 1.5098 \mathrm{E} 4$

$\mathrm{K}_{\mathrm{B}}$

4.4600E-3 $0 \quad 7.6497 \mathrm{E} 3$

$\mathrm{K}_{\mathrm{T}}$

$1.5100 \mathrm{E} 5 \quad 0 \quad 4.8817 \mathrm{E} 4$

$\mathrm{K}_{\mathrm{Z}}$

$2.1300 \mathrm{E} 1 \quad 0 \quad-2.063 \mathrm{E} 3$

Homogeneous Soot Oxidation

$$
\mathrm{C}_{\mathrm{s}}+\mathrm{OH}=\mathrm{CO}+\mathrm{H}
$$

$1.2200 \mathrm{E} 9$

0.5

0

Standard

This work 
* M stands for third-body collision partner

\section{Application to Kerosene fueled Thrust Chambers}

\section{Pennsylvania State University Tri-Propellant Combustor}

The maximum combustion chamber pressure achievable is usually associated with the combustion efficiency. The proposed thermophysics model is incorporated with a CFD code, FDNS $^{28,29}$, to compute the chamber pressure of an uni-element shear tri-axial tri-propellant combustor. $^{30}$ The test rig comprises of several sections, including an injector assembly, igniter, window and blank sections, and a nozzle assembly. Liquid RP-1 (LRP) is introduced through the central post of the tri-axial tri-propellant injector and swirled using a tangential swirl nut, whereas gaseous $\mathrm{H}_{2}\left(\mathrm{GH}_{2}\right)$ and gaseous $\mathrm{O}_{2}\left(\mathrm{GO}_{2}\right)$ are injected through the first and second (outer) annuluses, respectively. Details of the injector and the thrust chamber setup can be found in Ref's 14 and 30, whereas the chamber operating conditions used for model validation can be found in Ref. 30 .

FDNS is a multidimensional, multispecies, viscous flow, pressure-based reacting flow solver. It was developed at Marshall Space Flight Center (MSFC) and is continuously being improved by MSFC personnel and its supporting contractors. By incorporating and validating the proposed thermophysics formulation of kerosene combustion with a flow solver like FDNS, realistic performance computations can be performed to support the design of kerosene fueled injectors and thrust chambers, rather than relying on one-dimensional type of system performance calculations. FDNS solves simultaneous liquid-droplets-gas dynamics by 
combining the volume-of-fluid (VOF) and Eulerian/Lagrangian tracking methods into an unified algorithm for efficient calculation of multiphase flows at all speeds. The gas-liquid interface mass, momentum and energy conservation properties are modeled by continuum surface mechanisms. Details of the solution procedure for liquid-droplets-gas governing equations can be found in Ref. 29 and 31. In the VOF formulation, the weight-averaged conservation equations of mass, momentum, and scalar variables are formulated in an Eulerian framework. Current formulation considers the vaporization of liquid droplets into gases, but not the direct vaporization of liquid jet core into gases. An empirical mass stripping rate is applied to the VOF equation along the liquid-gas interface for liquid intact core resolution. The stripped liquid mass undergoes secondary breakup process to form smaller droplets. Lagrangian particle tracking method is used to treat the dynamics and heat/mass transfer of droplets, as computational parcels in a statistical sense. Energy and momentum are solved for each parcel for every species and relative enthalpy is the dependent variable for the droplet energy equation. For simplicity, parcel temperature is assumed to be constant at any time instant, but varies throughout its life expectancy via local heat transfer at the surface and vaporization. The heat capacity and latent heat of vaporization for liquid droplets are taken from Ref. 12 .

An axisymmetric thrust chamber is formulated and the computational domain covers the entire thrust chamber. As such, there is no ambiguity in the exit flow boundary condition once the throat flow is choked. For comparison purpose, a gaseous RP-1(GRP)/GH $/ \mathrm{GO}_{2}$ injector flowfield is computed first. After its convergence, the central-post flow passage is then replaced with $\mathrm{LRP}$ and a $\mathrm{LRP} / \mathrm{GH}_{2} / \mathrm{GO}_{2}$ injector flowfield computation is ensued. To start the calculation, a cold-flow thruster flowfield is computed first until the nozzle flow at the end of the combustor choked. The propellants in the mixing layers are then ignited by temporarily imposing hot spot 
with an elevated temperature $(1000 \mathrm{~K})$ in the flowfield. Once ignited, the flame propagates upstream and spreads downstream, whereas the final solution is not influenced by the location nor the added energy of the temporary hot spot. Due to the backward-facing step formation created by the injector faceplate and the side-wall, a flow recirculation forms to serve as a flame holder. A fixed mass flow rate boundary condition is imposed at the flow inlet and the inlet total enthalpy is conserved. The flow properties at the nozzle exit plane are extrapolated from those of the interior.

Figure 3 shows the computed scalar contours for the unielement $\mathrm{GRP} / \mathrm{GH}_{2} / \mathrm{GO}_{2}$ injector/combustor. Since the LRP jet is replaced with the GRP jet, there is no $\alpha_{\mathrm{LRP}}$ contours. The first three scalar contours are those of the reactants $\mathrm{GRP}, \mathrm{GH}_{2}$, and $\mathrm{GO}_{2}$. The mixing layers among GRP, $\mathrm{GH}_{2}$ and $\mathrm{GO}_{2}$ can be seen from those three contours. The high $\alpha_{\mathrm{O} 2}$ region is the flow recirculation region and the flame holder. The pressure contours show a nearly constant pressure inside the combustion chamber, which is expected since the jet speeds are subsonic. The next three contours show the mass fractions of the three major combustion products: $\mathrm{OH}$, $\mathrm{H}_{2} \mathrm{O}$ and $\mathrm{CO}_{2}$. The high concentration regions represent the flame front. Following is the $\mathrm{C}_{\mathrm{s}}$ mass fraction contours in which the incipient soot formation starts at the mixing layer. Most of the soot in the flame zone and nozzle are burned off by the heterogeneous and homogeneous oxidation reactions. Then there is the temperature contours and again the high temperature region represents the flame front. The close association of high $\mathrm{OH}$ concentration with high temperature emphasizes the importance of $\mathrm{OH}$ in initiating and sustaining the combustion.

Figure 4 shows the computed scalar contours for the uni-element $\mathrm{LRP} / \mathrm{GH}_{2} / \mathrm{GO}_{2}$ thrust chamber. The first contours show the LRP jet core and the subsequent trajectories and sizes of the droplets stripping from the liquid jet. The rest of the scalar contours resemble those of Fig. 3 
qualitatively, with some differences caused by the modeling of the liquid jet and droplets. For example, the length of GRP jet in Fig. 4 appears to be longer than that of Fig. 3, due to added delay of atomization and vaporization processes. The overall temperature of Fig. 4 is also lower than that of Fig. 3, caused by the latent heat loss of vaporizing liquid droplets. As such, the computed chamber pressure of $\mathrm{LRP} / \mathrm{GH}_{2} / \mathrm{GO}_{2}$ thruster is slightly lower than that of the $\mathrm{GRP} / \mathrm{GH}_{2} / \mathrm{GO}_{2}$ thruster, although the chamber pressure is nearly constant. In addition, the overall computed soot concentration appears to be lower in the $\mathrm{LRP} / \mathrm{GH}_{2} / \mathrm{GO}_{2}$ thruster.

Table 4 Comparison of chamber pressures.

\begin{tabular}{lc}
\hline \hline & $\mathrm{P}_{\mathrm{c}}$, atm \\
\hline test data & 34.2 \\
$\mathrm{GRP} / \mathrm{GH}_{2} / \mathrm{GO}_{2}$ model & 35.8 \\
$\mathrm{LRP} / \mathrm{GH}_{2} / \mathrm{GO}_{2}$ model & 33.5 \\
\hline
\end{tabular}

Table 4 shows the comparison of computed chamber pressures with that of the test. It can be seen that the computed chamber pressures from both models compare reasonably well with that of the measurement, although it was anticipated that the $\mathrm{GRP} / \mathrm{GH}_{2} / \mathrm{GO}_{2}$ model predicted chamber pressure would be slightly higher. On the other hand, empirical values for such parameters as the stripping rate and droplet size distribution were used for the multiphase flow model. Since latent heat decreases as chamber pressure increases, it is postulated that states of "liquid" and "gas" are indistinguishable under high-pressure rocket chamber environments. This hypothesis seems to agree with the observation ${ }^{32}-$ a faster rate of gasification is associated with elevated chamber pressures - of the combustion time for a RP-1 droplet. As such, the solution 
from the gaseous phase model is probably as justifiable as that of the multiphase flow model, under the rocket operating conditions.

The discussion herein indicates that the proposed thermophysics model is validated to support the design of kerosene-fueled injectors and combustors. It also needs to be pointed that the reasonable agreement of the chamber pressures in Table 4 is attributed to the proposed thermophysics characterization rather than the choice of single-phase or multiple-phase flow options.

\section{NASA MSFC 40k Kerosene Fueled Thruster}

The proposed kerosene combustion thermophysics model is incorporated with FDNS for computing and comparing the predicted radiative heat fluxes with those of a measurement for a kerosene fueled thruster plume. The radiometers of the test are located downstream of the thruster exit plane and the line-of-sights are perpendicular to the plume centerline. Figure 5 shows typical computed scalar contours for temperature, $\mathrm{CO}_{2}, \mathrm{H}_{2} \mathrm{O}$, and $\mathrm{C}_{\mathrm{s}}$ mass fractions. The four vertical lines across the plume indicate the line-of-sights of the radiation measurement where the first vertical line from the nozzle exit plane is designated as the line-of-sight of radiometer $\mathrm{Q}_{1}$, and so on. The line-of-sight of radiometer $\mathrm{Q}_{2}$ is closest to the computed plume Mach disc. The computational model is an axisymmetric formulation and the computational domain is five times longer than that is shown to include enough plume for wide-angle radiation calculations. Details of injection layout in the combustor such as the multiple fuel and oxidizer injection ports, a central fuel jet, and a wall film coolant jet are included in the computation. The scalar contours in Fig. 5 show striations of those jets converging near the throat, expanding in nozzle and thrusting into atmosphere. The interaction of the exhaust plume with the initially 
quiescent air creates an eddy-like mixing layer where the remaining reactants afterburns. The film coolant essentially forms a protective, sooty layer along the thruster wall and afterburns in the outer mixing layer along with other reactants, as shown in the $\mathrm{C}_{\mathrm{s}}$ contours. Also shown in the $\mathrm{C}_{\mathrm{s}}$ contours is a central soot core resulting from the central fuel jet injection. The triple shocks (lip shock, Mach disc, and reflect shock) are clearly seen in the temperature contours. Overall, the computed thermo-flowfield appears to be reasonable. These scalar contours are plotted because $\mathrm{CO}_{2}, \mathrm{H}_{2} \mathrm{O}$, and $\mathrm{C}_{\mathrm{s}}$ are major radiators of a keosene fueled thruster plume. The local concentrations of these radiators and temperature decide the strength of the radiation.

Table 5. Comparison of computed radiation with that of test measurement.

\begin{tabular}{lcccc}
\hline & $\mathrm{Q}_{1}$ & $\mathrm{Q}_{2}$ & $\mathrm{Q}_{3}$ & $\mathrm{Q}_{4}$ \\
\hline 0 & 4 & 180 & 4 & 5.5 \\
$\mathrm{Q}$, test & $10-12$ & $5.4-6.0$ & $75-95$ & $>70$ \\
Q, without rxn & 120.7 & 2.9 & 55.7 & 34.0 \\
Q, irrev. rxn & 8.4 & 1.9 & 26.5 & 25.4 \\
Q, rev. rxn & 14.1 & 5.4 & 131.9 & 117.3 \\
\hline
\end{tabular}

Parametric studies are performed to study the effect of homogeneous soot oxidation on the radiation signals. Table 5 shows the comparison of computed radiation with that of the test data. The hot-firing of a rocket thruster is transient in nature and the radiation signals are taken when the chamber pressure reaches an approximate constant. As a result, the plume boundary layer is unsteady and the goodness of the radiation measurement often depends on the view angle of the radiometer. It can be seen from the view-angle row of Table 5 that only radiometer $\mathrm{Q}_{2}$ has a wide view-angle (180 deg) and is least likely to be influenced by the unsteady motion of the free shear layer. On the other hand, the measurements from other three radiometers are of the narrow-angle category thereby are more susceptible to the unsteady plume motion. It is also 
noted from post-test examination that there was some shrinkage of the throat due to soot accumulation, resulting in some slight drifting of the chamber pressure.

From Table 5, the thermophysics model using the reversible homogeneous soot oxidation reaction produces the best comparison with the wide-angle data and reasonable comparison with those of the narrow-angle measurements (two out of three). The overprediction at $\mathrm{Q}_{3}$ is attributed to the combination of the narrow view-angle and the unsteadiness of the free shear layer. On the other hand, when the original irreversible form of the homogeneous soot oxidation reaction is used, soot burns off quickly and all the radiations are underpredicted. Without the homogeneous soot oxidation, the model predictions disagree with the measurement in all respects. The result from Table 5 shows that the proposed thermophysics model provided reasonable plume properties. It also emphasized the importance of including the reversible homogeneous soot oxidation reaction in the kerosene combustion kinetics model.

\section{Conclusion}

A thermophysics characterization of kerosene combustion is developed for incorporation with advanced computational fluid dynamics methodologies for kerosene-fueled rocket engine design calculations. The model consists of a surrogate fuel model representing kerosene/RP-1 fuels, a thermodynamics model anchored with the heat of combustion, and an efficient quasi-global kinetics model describing the combustion processes, including soot formation and oxidation reactions. The rationale of the modeling approach is given. The benchmark results indicate that the proposed thermophysics model can be used to support the kerosene fueled thrust chamber design applications and plume definitions. 


\section{Acknowledgment}

Part of this study is performed under the Rocketdyne - NASA MSFC Cooperative Agreement for Reusable Launch Vehicle Technology Program. The development of FDNS code is partially supported by the NASA MSFC Long Term High Payoff Technology Program. Francisco Canabal provided the $40 \mathrm{~K}$ thruster grid and Young-Ching Lee performed the plume radiation calculation.

\section{$\underline{\text { References }}$}

${ }^{1}$ Wang, T.-S., McConnaughey, P., Warsi, S., and Chen, Y.-S., "Computational Pollutant Environment Assessment from Propulsion System Testing," Journal of Spacecraft and Rockets, Vol. 33, No. 3, May-June 1996, pp.386-392.

2 Anon. CPIA/M4, Liquid Propellant Manual, Dec., 1989.

${ }^{3}$ Anon. Military Specification MIL-R-25576C. Propellant, Kerosene, Feb., 1967.

4 Amsden, A.A., "KIVA-III: A KIVA Program with Block Structure Mesh for Complex Geometry," LA-12503-MS, 1993.

${ }^{5}$ Farmer, R.C. and Anderson, P.G., "Soot Formation in Rocket Propulsion Systems," SECA-FR-9512, SECA, Inc., June 1995.

6 Svehla, R.A., and McBride, B.J., "FORTRAN IV Computer Program for Calculation of Thermodynamic and Transport Properties of Complex Chemical Systems," NASA TN D-7056, Jan. 1973.

${ }^{7}$ Harsha, P.T., Edelman, R.B., and Farmer, R.C., "Fundamental Combustion Technology for Ramjet Applications - Technology Review," CPIA pub. 363, VOL II, Sept. 1982. 
${ }^{8}$ Lawver, B.R., "Testing of Fuel/Oxidizer-Rich High-Pressure Preburners," Final Report, NASA CR-16544, NASA-Lewis Research Center, May 1982.

${ }^{9}$ Nickerson, G.R., and Johnson, C.W., "A Soot Prediction Model for the TDK Computer Program," AIAA Paper 92-3391, July, 1992.

${ }^{10}$ Sutton, George, P., Rocket Propulsion Elements - An Introduction to the Engineering of Rockets, fifth edition, John Wiley \& Sons, Inc., 1986.

${ }^{11}$ Nelson, W.L., Petroleum Refinery Engineering, fourth edition, McGraw-Hill, New York, 1958.

${ }^{12}$ Lefebvre, A.H., Atomization and Sprays, Hemisphere Publishing Corp., New York, NY, 1989.

${ }^{13}$ Hautman, D.J., Dryer, F.L., Schung, K.P., and Glassman, I., "A Multiple-step Overall Kinetic Mechanism for the Oxidation of Hydrocarbons," Combustion Science and Technology, Vol. 25, 1981, pp. 219-235.

${ }^{14}$ Moser, M.D., Merenich, J.J., Pal, S., and Santoro, R.J., "OH-Radical Imaging and Velocity Field Measurements in a Gaseous Hydrocarbon/Oxygen Rocket," AIAA Paper 93-2036, June 1993.

15 Edelman, R.B., and Harsha, P.T., "Laminar and Turbulent Gas Dynamics in Combustors Current Status," Progress in Energy and Combustion Science, Vol. 4, 1978, pp. 1-62.

${ }^{16}$ Wang, T.-S., Farmer, R.C., and Edelman, R.B., "Turbulent Combustion Kinetics for Complex Hydrocarbon Fuels," AIAA Paper 88-0733, Jan. 1988.

${ }^{17}$ Wang, T.-S., Farmer, R. C., and Tucker, P. K., "Turbulent Hydrocarbon Combustion Kinetics - Stochastic Modeling and Verification," AIAA Paper 89-0486, Jan., 1989.

${ }^{18}$ Wang, T.-S., Matula, R. A., and Farmer, R. C., "Combustion Kinetics of Soot Formation from Toluene," Eighteenth Symposium (International) on Combustion/The Combustion Institute, pp. 1149-1158, 1981. 
${ }^{19}$ Wang, T.-S., "Soot Formation from Toluene," Ph.D. Dissertation, Louisiana State University, 1980.

${ }^{20}$ Frenklach, M., Clary, D.W., and Ramachandra, M.K., "Shock Tubes Study of the Fuel Structure Effects on The Chemical Kinetic Mechanisms Responsible for Soot Formation, Part 2," NASA CR174880, May 1985.

${ }^{21}$ Farmer, R.C., Edelman, R.B., and Wong, E., "Modeling Soot Emissions in Combustion Systems," Particulate Carbon Formation during Combustion, edited by Siegla, D.C., and Smith, G.W., Plenum Press, 1981, pp. 299-320.

${ }^{22}$ Nagle, J., and Strickland-Constable, "Oxidation of Carbon between $1000-2000^{\circ} \mathrm{C}$," Proceedings of Fifth Carbon Conference, Vol. 1, 1962, pp.151-164.

${ }^{23}$ Hiers III, R.S., "Soot Particle Thermal Nonequilibrium in Afterburning Plumes," 1995 JANNAF Exhaust Plume Technology Subcommittee Meeting, Vol. I, CPIA Publication 632, 1995, pp. 133145.

${ }^{24}$ Olander, D.R., Siekhaus, W. Jones, R., and Schwarz, J.A., "Reactions of Modulated Molecular Beams with Pyrolytic Graphite. I. Oxidation of the Basal Plane," The Journal of Chemical Physics, Vol. 57, No. 1, 1972, pp. 408-420.

${ }^{25}$ Roth, P., Brandt, O., and Gersum, S. Von, "High temperature Oxidation of Suspended Soot particles Verified by $\mathrm{CO}$ and $\mathrm{CO}_{2}$ measurements," Twenty-Third Symposium (International) on Combustion/The Combustion Institute, 1990, pp. 1485-1491.

${ }^{26}$ Slack, M.W., Tyler, S.A., Diestel, M.J., and P.D. Thomas, "Carbon Oxidation kinetics in Low Altitude Plumes: Rate Kinetics, Particle Heating and Plume Signature Implications," Proceedings of 1995 JANNAF Exhaust Plume Technology Subcommittee Meeting, Vol. 1, CPIA Publication 632, 1995, pp. 119-132. 
27 Lee, M.J., "A Computational Study of the Effects of Carbon Particles on IR Radiation: Comparison of the Results with Experimental Data," Proceedings of $32^{\text {nd }}$ JANNAF Combustion Subcommittee Meeting, Vol. III, CPIA Publication 631, 1995, pp. 369-379.

${ }^{28}$ Chen, Y.-S., "FDNS - A General Purpose CFD Code - User's Guide”, Version 4.0, ESI-TR-97-

01, Engineering Sciences, Inc., May 1997.

${ }^{29}$ Chen, Y.-S., Shang, H.-M., Chen, C.-P., and Wang, T.-S., "General Numerical Model for Liquid Jet Atomization Applications," Joumal of Propulsion and Power, Technical Notes, Vol. 14, No. 4, July-August, 1998, pp. 581-584.

${ }^{30}$ Clemons, K., Schmidat, M., Mouis, A.G.F., Ni, T., Pal, S., and Santoro, R.J., "Tripropellant Combustion Using RP-1/GO2/GH2: Drop and Injector Studies," Proceedings of 32nd JANNAF Combustion Subcommittee Meeting and Propulsion Engineering Research Center 7th Annual Symposium, Vol. II, CPIA Publication 631, pp. 199-207, MSFC, AL, Oct. 23-27, 1995.

${ }^{31}$ Chen, Y.-S., Shang, H.-M., Liaw, P., Chen, C.P., and Wang, T.S., "A Combined EulerianVOF-Lagrangian Method for General Gas-Liquid Flow Applications," Numerical Heat Transfer, Vol. 30, Pt. B, 1996, pp. 409-422.

${ }^{32}$ Farmer, R.C., Anderson, P.G., Chang, G.C., Myruski, B.L., and Pike, R.W., "Propulsion Chemistry for CFD Applications," Final Report, SECA-FR-97-08, SECA, Inc., Huntsville, AL, Sept. 1997. 


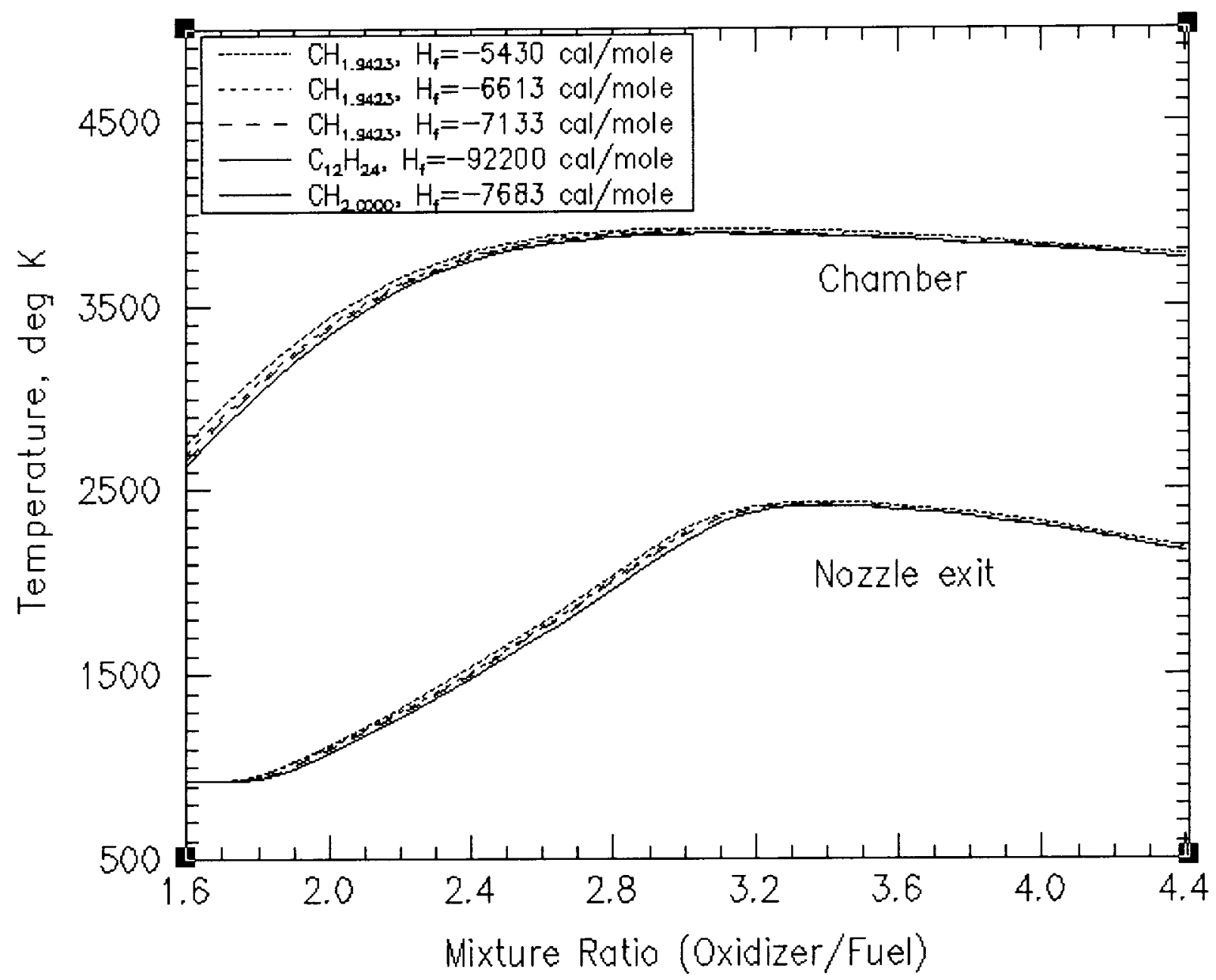

Fig. 1 Comparison of the RD-170 chamber and nozzle exit temperatures. 


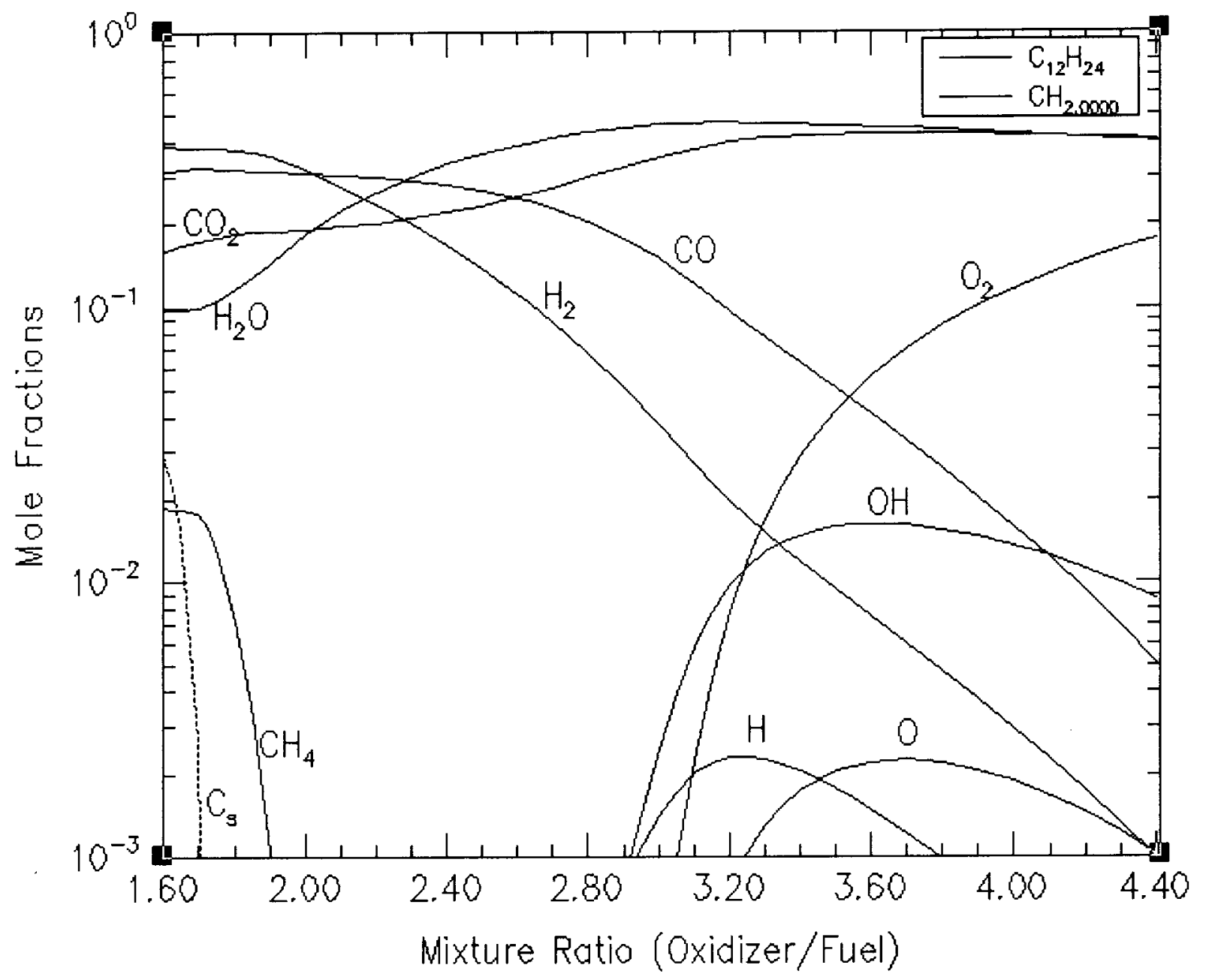

Fig. 2 The RD-170 nozzle exit gas composition. 


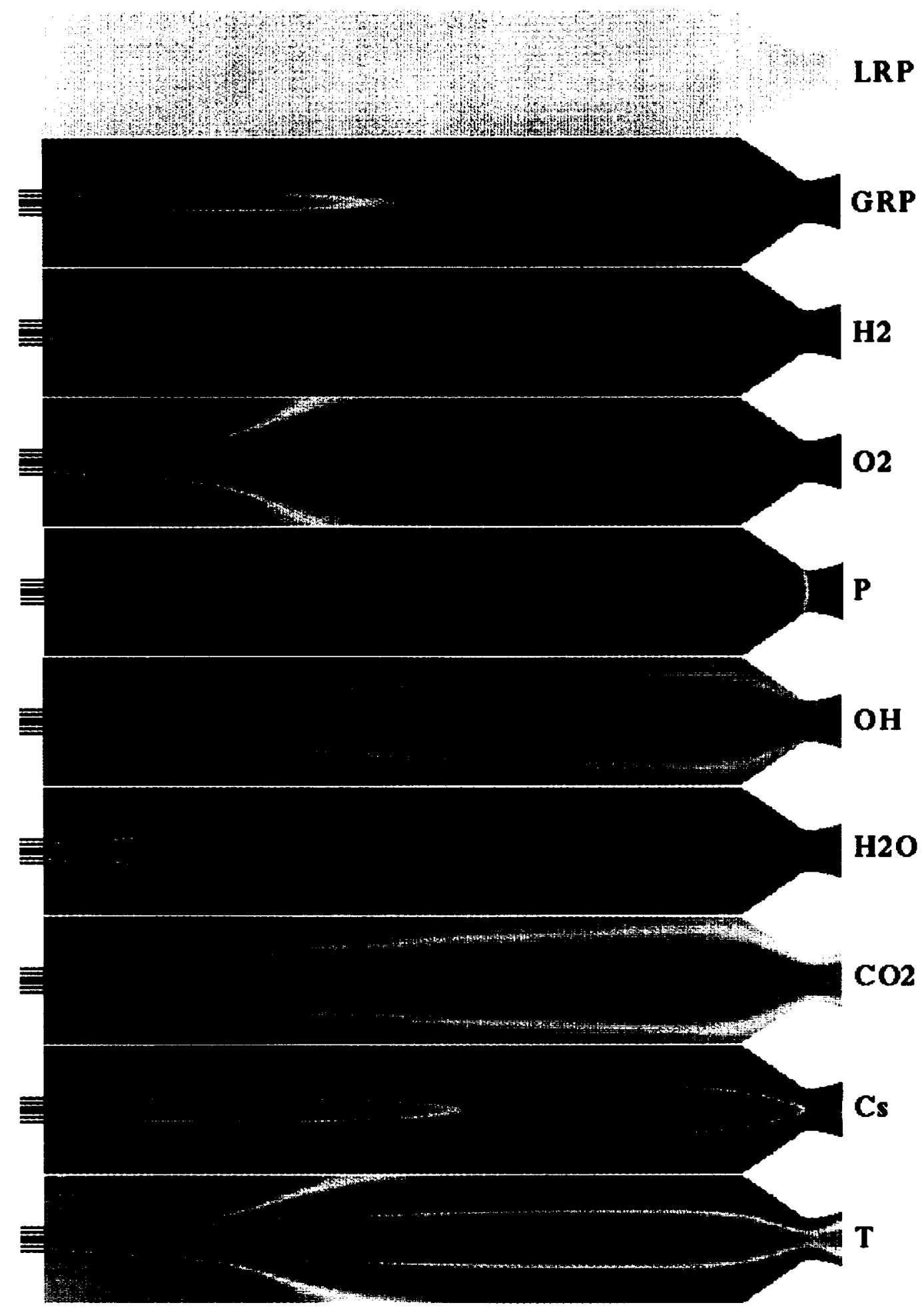

Fig. 3 Computed scalar contours for an unielement GRP/GH $/ \mathrm{GO}_{2}$ injector/combustor: $\alpha_{\mathrm{LRP}}, 0$ - 1 ; $\alpha_{\mathrm{GRP}}, 0-1 ; \alpha_{\mathrm{H} 2}, 0-1 ; \alpha_{\mathrm{O} 2}, 0-1 ; \mathrm{P}, 4.7-34.2 ; \alpha_{\mathrm{OH}}, 0-0.12 ; \alpha_{\mathrm{H} 2 \mathrm{O}}, 0-0.87 ; \alpha_{\mathrm{CO} 2}, 0-0.39 ; \alpha_{\mathrm{Cs}}, 0$ -0.17 ; and $\mathrm{T}, 251-3528$. 


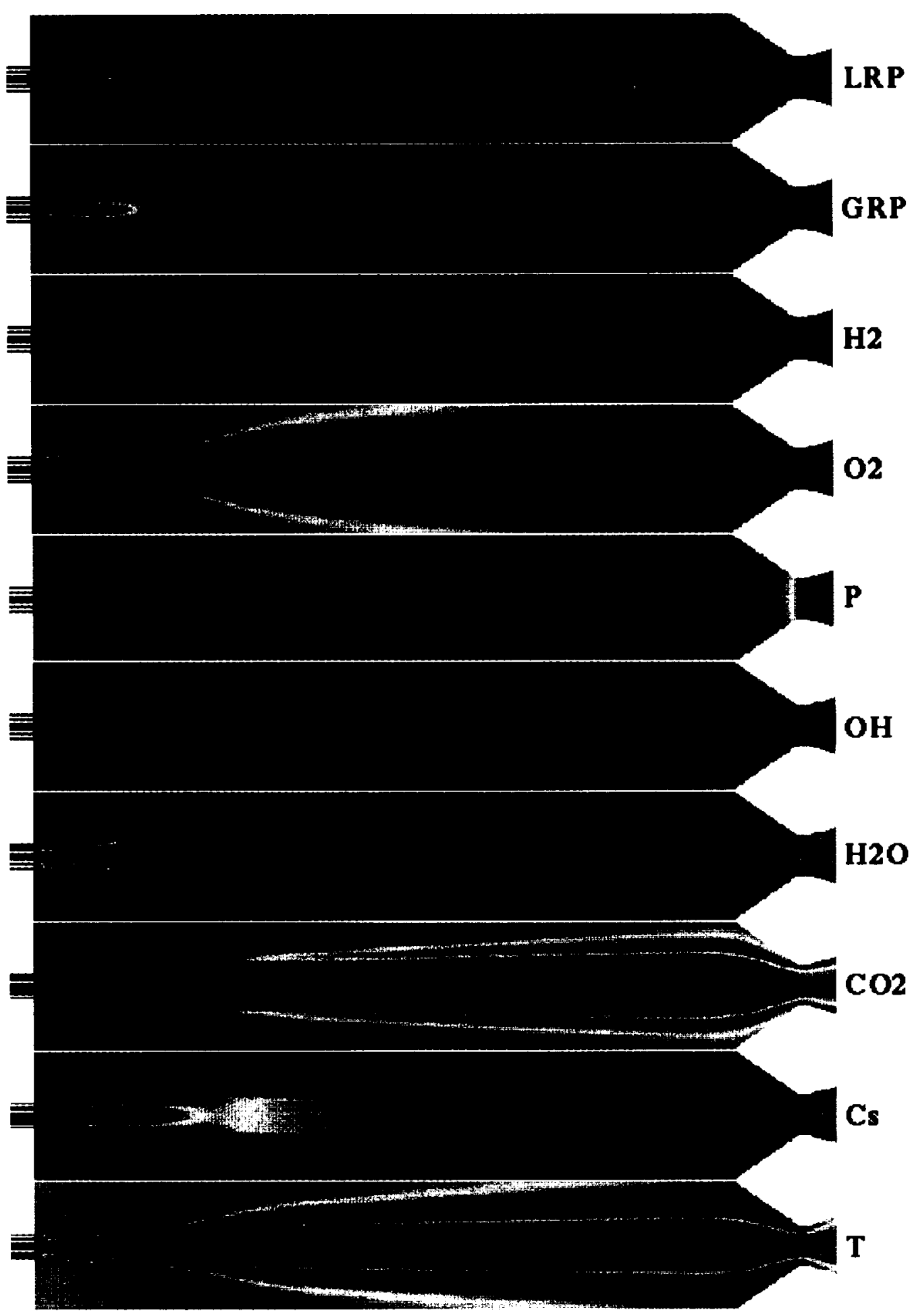

Fig. 4 Computed scalar contours for an unielement $\mathrm{LRP} / \mathrm{GH}_{2} / \mathrm{GO}_{2}$ injector/combustor: $\alpha_{\mathrm{LRP}}, 0-1$; $\alpha_{\mathrm{GRP}}, 0-1 ; \alpha_{\mathrm{H} 2}, 0-1 ; \alpha_{02}, 0-1 ; \mathrm{P}, 4.7-34.2 ; \alpha_{\mathrm{OH}}, 0-0.12 ; \alpha_{\mathrm{H} 2 \mathrm{O}}, 0-0.87 ; \alpha_{\mathrm{CO} 2}, 0-0.39 ; \alpha_{\mathrm{Cs}}, 0$ -0.17 ; and $\mathrm{T}, 251-3528$. 


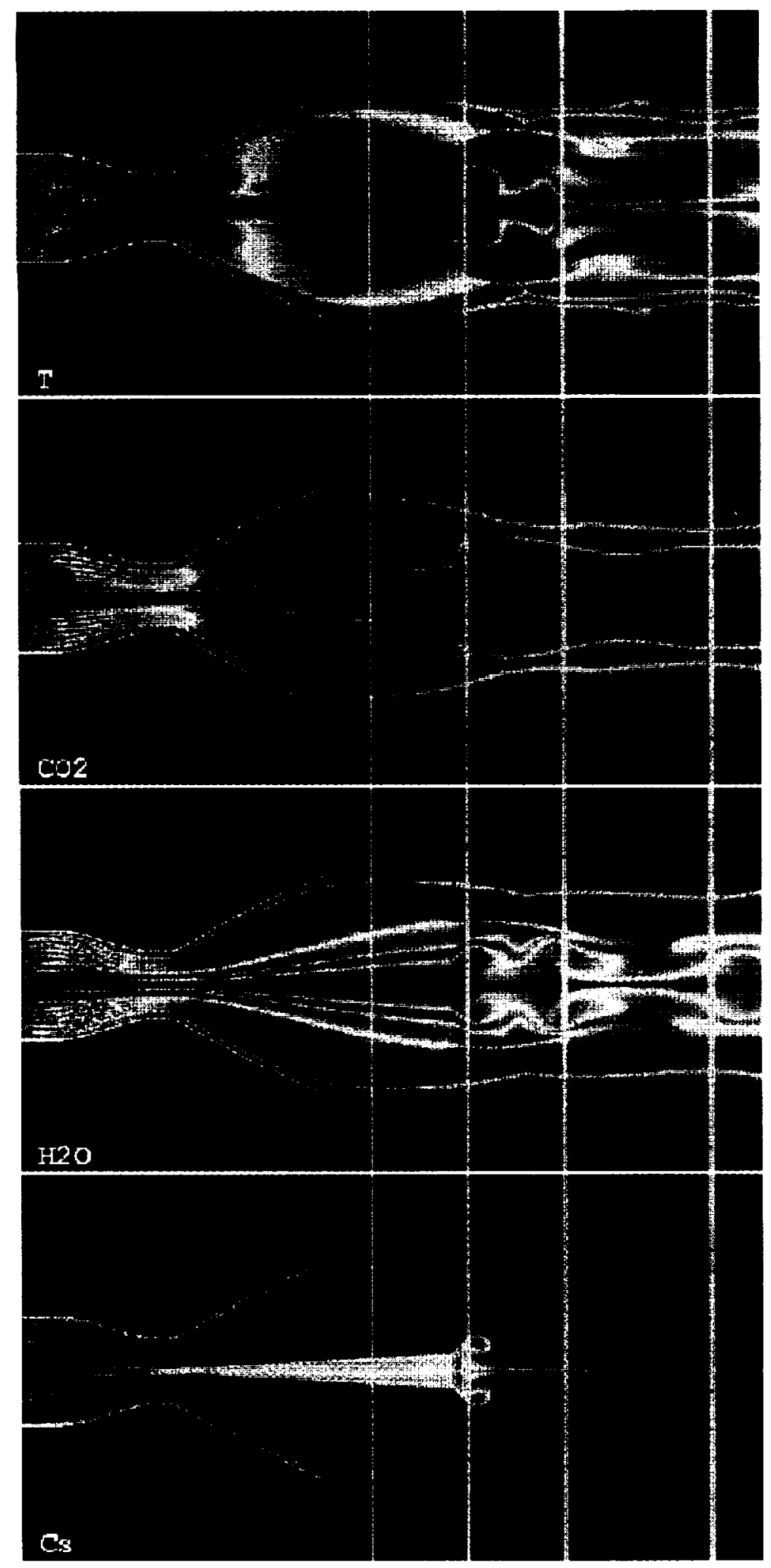

Fig. 5 Computed scalar contours for a kerosene fueled thruster and plume: T, $186-6089 ; \alpha_{\mathrm{CO} 2}, 0-$ $0.5 ; \alpha_{\mathrm{H} 2 \mathrm{O}}, 0-0.3 ;$ and $\alpha_{\mathrm{CS}}, 0-0.3$. 